\title{
The Effect of Two Traffic Situations on the Behavior and Performance of Cows in an Automatic Milking System
}

\author{
G. G. N. Hermans, ${ }^{\star}$ A. H. Ipema, ${ }^{*}$ J. Stefanowska, ${ }^{\star}$ and J. H. M. Metz† \\ *Institute of Agricultural and Environmental Engineering, \\ PO Box 43, 6700 AA, Wageningen, \\ The Netherlands \\ †Wageningen University, Farm Technology Group, \\ PO Box 43, 6700 AA, Wageningen, \\ The Netherlands
}

\begin{abstract}
Two cow traffic situations were tested sequentially in an automatic milking system (AMS) for effects on cow behavior, effective use of the barn, and milking capacity. The first situation was forced cow traffic: 63 cows had to pass through the AMS to go from the lying area to the feeding area. The second was semiforced cow traffic: 67 cows ( 60 cows from before) had free access to a forage feeding area at one end of the barn but could only access an area with concentrate feeders by passing through the AMS. Behavior of all cows was monitored as well as for two subsets of cows present in both situations: 8 cows with low frequency vs. 7 cows with high frequency of visits to the AMS. In each situation, cows were observed for $72 \mathrm{~h}$. Cow locations and behavior were noted at 10-min intervals for all cows and individually for the selected cows. In semiforced traffic, the herd readily used the freely accessible forage feeding area, ate longer $(17.4 \%$ of the day vs. $15.1 \pm 0.59 \%)$, and stood less in freestalls (9.0 vs. $11.8 \pm 0.30 \%)$ than when cow traffic was forced. Nonmilking visits to the AMS tended to decrease, whereas milking visits remained unchanged in the semiforced situation. The subset of cows that visited the AMS more often had fewer nonmilking visits (1.8 vs. $4.2 \pm 0.7)$ in the semiforced traffic situation whereas cows with low frequency of visits to the AMS had a nonsignificant increase (1.5 vs. 1.0) in nonmilking visits. Cows that visited the AMS frequently used the forage feeding area and the lying area next to it more than low frequency cows and use of those areas increased further during the semiforced situation. The semiforced cow traffic was deemed more desirable than forced cow traffic both for cows and for the capacity of the automatic milking system.
\end{abstract}

(Key words: automatic milking system, cow traffic, behavior, milking frequency)

Received July 11, 2002.

Accepted January 17, 2003.

Corresponding author: A. H. Ipema; bert.ipema@wur.nl.
Abbreviation key: AMS = automatic milking system, ES1 = experimental situation one, ES2 = experimental situation two, Hfreq cows = cows visiting the AMS with high frequency, Lfreq cows = cows visiting the AMS with low frequency.

\section{INTRODUCTION}

Previous studies have examined free and forced cow traffic in barns with automatic milking systems (AMS) (Ketelaar-de Lauwere 1992; Metz-Stefanowska et al., 1992; Ketelaar-de Lauwere et al., 1998; 2000; Harms et al., 2001). In forced cow traffic, the only way cows can go from one part of the barn (usually the lying area) to the other (usually the feeding area) is by passing through the AMS and back through one-way gates. In free cow traffic, cow visits to the AMS are not guided in this way and the cows can move freely in the barn from one part to the other without having to visit the AMS. The cows are primarily encouraged to visit the AMS by being rewarded with a portion of concentrates there (Prescott et al., 1998). Ketelaar-de Lauwere et al. (1998) concluded that forced cow traffic better guarantees the required AMS visiting frequency. However, free cow traffic may be preferable, because cows have more freedom of movement and more opportunity to perform the synchronized behavior that is a common tendency for a herd (Hurnik 1992).

To find the optimal cow traffic situation, researchers have studied barn layouts that are intermediate between the free and forced cow traffic situations. Harms et al. (2001) compared free cow traffic, forced cow traffic and selectively forced cow traffic in a herd of 48 cows. In the selectively forced situation, cows had access to the feeding area via the AMS but also through selection gates with cow identification between the lying and feeding areas. The cows were only allowed through the selection gates if they did not have to be milked. Under the conditions investigated, the selectively guided cow traffic was the best solution. This system does have a drawback, however: the cows are only allowed through 
the selection gate and the AMS at variable, computerprogrammed times that may not always be clear to them. As a result, the cows may become uncertain and the expensive selection gates may be used suboptimally. In the study we describe, we compared forced cow traffic with a semiforced cow traffic situation in which cows could eat forage in a part of the feeding area freely accessible from the lying area. To get concentrates, the cows had to go through the AMS to the feeding area. In the AMS they were rewarded with a portion of concentrate when milked, and in the feeding area they found the forage and concentrate feeders. This layout was based on a layout of the barn and a selection unit in front of the AMS described by Ipema (1997). In Ipema's study the feeding area was divided into two areas. In one area only forage could be eaten while in the other there was forage and concentrate. A selection unit sited in the lying area selected whether a cow should be milked and whether she should receive concentrate. If the cow needed to be milked she was sent to the AMS, if not she was sent to the feeding area appropriate to the concentrate decision (yes or no). We used the two feeding areas in our study, but instead of using a selection unit we placed the AMS en route to the concentrate dispensers. Thus, in this semiforced situation the cows could always go to the feeding area for forage and there was no uncertainty about the movement allowed in the barn.

We wanted to know which situation was best for the cow's welfare and for the total number of milkings in the AMS. We hypothesized that the semiforced cow traffic situation would be better for the cows because in this situation they have more freedom to eat forage and to synchronize their behavior. Further, we assumed that in this situation there would be fewer nonmilking visits and therefore that better use would be made of the AMS' milking capacity.

\section{MATERIALS AND METHODS}

\section{Animals, Housing, Feeding and Milking}

The experiment was carried out in a cubicle house with a milking robot with two milking stalls (Prolion/ AMS Liberty) at the Ossekampen experimental farm of Wageningen University and Research Center. The herd was managed under commercial conditions. This entailed adjusting the concentrate ration every week in accordance with milk production.

The experiment ran from January through March 2001. In the first week of January we started using the robot and all 73 Holstein-Friesian cows were milked with a milking robot for the first time. In the second and third weeks there were some changes to the original herd: some cows that had just calved were added, and others were dried off or culled. As a result there were 63 cows for the experiment starting with the first experimental situation (ES1). This herd of 63 cows consisted of 28 first parity cows and 35 second or higher parity cows, which were on average $109 \pm 8.9 \mathrm{DIM}$ and produced $27 \pm 0.9 \mathrm{~kg}$ of milk per day. After ES1, seven cows were added to the group (they had previously been milked in a conventional milking parlor or had just calved) and three cows were removed (dried off). As a result, in the second experimental situation (ES2) there was a group of 67 cows (28 first parity and 39 second or higher parity). Fifteen cows were selected from the original herd and studied as two subgroups: the cows with either a high frequency of visits (Hfreq) and those with a low frequency of visits (Lfreq) to the AMS. The average number of visits paid to the AMS per day during the selection week was $6.9 \pm 0.34$ for the Hfreq cows $(\mathrm{n}=7)$ and $3.0 \pm 0.13$ for the Lfreq cows $(\mathrm{n}=8)$. The parity and number of days in lactation of the cows in the selected groups were comparable.

The cows were kept in a cubicle (freestall) house with a feeding area, a lying area, a waiting area and an AMS with its entrance in the lying area and its exit in the feeding area (Figure 1). The floor consisted of concrete slats that were cleaned automatically by a manure scraper at 2 -h intervals. There were 69 cubicles (freestalls) available in the lying area and there were 61 feeding places at the feeding gate. Although there were fewer feeding places than cows, they were never all occupied at once. Water was provided ad libitum at eight locations in the barn: there were five drinking places at the feeding gate and three drinking places in the lying area near the one-way gates (Figure 1).

A mixture of $70 \%$ grass silage and $30 \%$ maize silage was provided once a day between $0800 \mathrm{~h}$ and $0900 \mathrm{~h}$ along the feeding gate and was available round the clock. The forage was pushed up against the feeding fence three times a day (at 0600, 1700, and $2200 \mathrm{~h}$ ).

The cows received $0.5,1.0$, or $2.0 \mathrm{~kg}$ of concentrate per milking in the AMS, depending on their daily ration. The remaining part of their daily ration was fed in two concentrate feeders in the feeding area (Figure 1). The concentrate in the feeders was allocated in three periods of $8 \mathrm{~h}$, with a maximum of $3.5 \mathrm{~kg}$ per period (in one allocation). The first period started at $0830 \mathrm{~h}$.

The AMS was always accessible except during cleaning at 0730,1500 , and $2200 \mathrm{~h}$ for about $40 \mathrm{~min}$ each time. The milk was collected three times a week, after which there was a major cleaning at $0730 \mathrm{~h}$, lasting $90 \mathrm{~min}$. In the AMS the cows could be milked with a minimum milking interval of $6 \mathrm{~h}$. Three times a day (just before the cleanings) any cows that had not been milked in the previous $12 \mathrm{~h}$ were led to the AMS. After a failed milking cows were sent back to the waiting 
Experimental situation 1: Forced cow traffic (ES1)

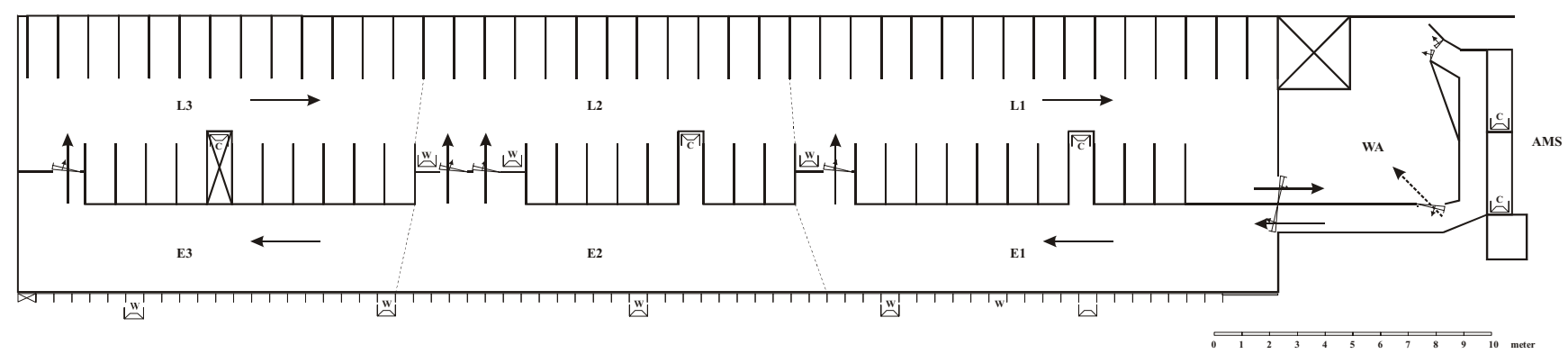

Experimental situation 2: Semi-forced cow traffic (ES2)

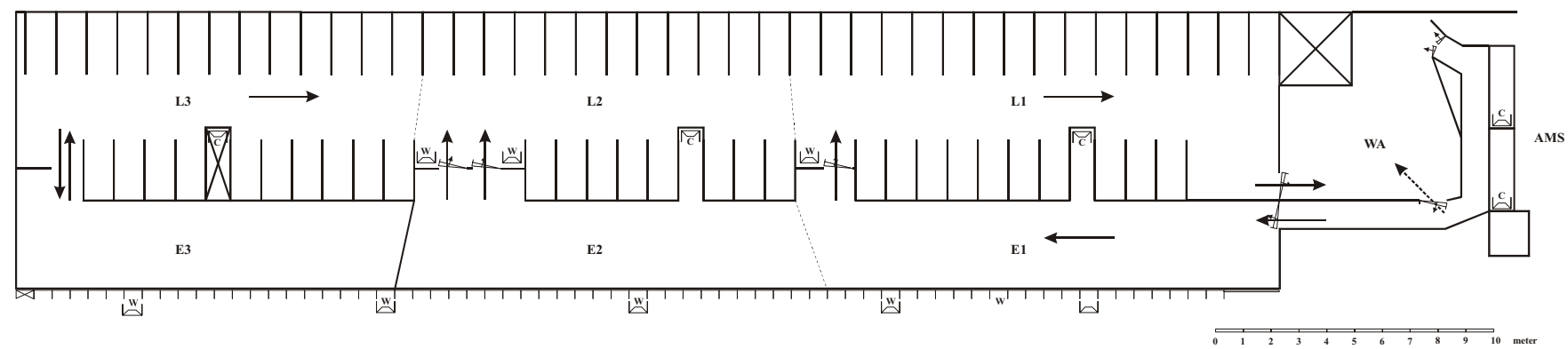

Figure 1. Plan of the barn in the experimental situations (ES1 and ES2) with forced and semiforced cow traffic, respectively.

Experimental situation 1: Forced cow traffic (ES1)

Experimental situation 2: Semiforced cow traffic (ES2)

The eight different areas: Milking robot (AMS) = from double-door gate until after the gate back to the waiting area; Waiting area (WA) $=$ area in front of the AMS; Feeding area $1(\mathbf{E 1})=$ feeding area close to the AMS; Feeding area $2(\mathbf{E 2})=$ feeding area in the middle of the barn; Feeding area $3(\mathbf{E 3})$ = feeding area far from AMS, with free admittance from lying area during ES2; Lying area 1 (L1) = lying area close to the AMS; Lying area $2(\mathbf{L 2})=$ lying area in the middle; Lying area $3(\mathbf{L 3})=$ lying area furthest from AMS.

$\mathrm{C}=$ concentrate feeder,

$\mathrm{W}=$ water trough,

solid arrow = direction of cow movement in the barn, and

broken arrow $=$ after a failed attachment, the cow is sent back to the waiting area via this gate.

area (Figure 1). After a second failed milking the animal was sent to the eating area.

The barn was permanently illuminated by a double row of fluorescent lighting augmenting the daylight admitted through the windows and roof.

\section{Experimental Design}

Experimental situation one (ES1): Forced cow traffic. In this situation all the passages between the feeding and the lying areas (Figure 1) had one-way gates (four in total), which cows used when passing from the feeding to the lying area. If they wanted to go from the lying area to the feeding area, they had to pass through the waiting area and the AMS. This situation lasted for $3 \mathrm{wk}$ : the first $2 \mathrm{wk}$ were for habituation, and in the last week there were $3 \mathrm{~d}$ of observation. The continuous observation period started at $0600 \mathrm{~h}$ and lasted for $72 \mathrm{~h}$.
Experimental situation two (ES2): Semiforced cow traffic. In this situation the part of the feeding area furthest from the AMS (feeding area three with 18 feeding places) was separated from the rest of the feeding area by a fence so that it was only accessible from the lying area (the last one-way gate was removed). This allowed the cows to go from the lying area to the feeding area at the end of the barn without going through the AMS. In this feeding area the cows could eat forage but there was no concentrate feeder. For concentrate they still had to go through the AMS to the large feeding area. As in ES1, this situation was also imposed for $3 \mathrm{wk}, 2$ wk of which were for habituation, followed by $3 \mathrm{~d}$ of observation.

General. $3 \mathrm{wk}$ before the start of the experiment the milking robot was activated and the cow traffic situation was managed in the same way as in ES1 (forced cow traffic). 
In the first week of $\mathrm{ES} 1$ all the cows visiting the milking robot on average more than 6 times/day and most of the cows visiting the milking robot on average less than 3.5 times/day were selected. These became the Hfreq and Lfreq groups noted above. Two cows that visited the AMS less than 3.5 times/day were about to be dried off, so they were not selected. A white halter was used to mark the selected cows so that they could easily be found in the herd. During the observation days the ambient temperature was measured every hour. The mean daily temperature was $8.9 \pm 0.4^{\circ} \mathrm{C}$ in $\mathrm{ES} 1$ and $6.8 \pm 0.4^{\circ} \mathrm{C}$ in $\mathrm{ES} 2$.

Data from the AMS. In the AMS data were collected for each cow milked in it. The milking intervals were used to check whether any cows had not been milked for over $12 \mathrm{~h}$; such cows were then fetched and milked. The production data were used to determine the daily concentrate ration (high-yielding cows were given more concentrate). The data available were the number of visits made to the AMS per cow and their type (milking visit, nonmilking visit and failed milking). In calculating the number of visits, a failed milking followed by a good milking was counted as one milking visit and a failed milking followed by a second failed milking was counted as one failed milking. This was done to make sure that only the voluntary number of visits was counted.

Behavioral observations. For this purpose the barn was divided virtually into eight areas: the AMS, the waiting area, three feeding areas, and three lying areas (Figure 1). This imaginary division of the feeding and the lying areas into three gave an indication of distance to the AMS. Feeding area 1 was near the AMS and feeding area 3 was furthest away. The three parts of the lying area were numbered following the same principle (Figure 1).

In the observation period we used 10-min scan sampling to record the number of cows in each area and their activity. We recorded eating (cow with head through feeding gate), lying, standing on the floor, or standing in freestalls. The selected cows were observed similarly but their data were individually recorded, i.e. we recorded where each selected cow was and what she was doing there.

Statistical analyses. The data were analyzed with the Genstat 5 statistical package (Genstat 5 Committee, 1999). For the behavioral observations ANOVA was done to test for differences between situations, groups, days and parts of the day. The situations (ES1 and ES2), groups (Hfreq and Lfreq) and the interaction between situation and group were used in the treatment structure. The day and part of the day (there were $3 \mathrm{~d}$ per situation, divided into four periods of $6 \mathrm{~h}$ ) were used as blocks.
The response variables, expressed in percentage of time spent lying, eating (also in areas 1,2, and 3) and standing (also on the floor, in freestalls, in areas 1, 2, and 3 and in the waiting area and AMS), were analyzed using the model:

$$
\mathrm{y}=\mathrm{m}+\mathrm{t}+\varepsilon
$$

where $\mathrm{y}$ is the response variable, $\mathrm{m}$ is the overall mean, $t$ is the treatment effect and $\varepsilon$ is the residual variance.

The ANOVA assumes that the response variable is normally distributed and has a constant variance. To ensure that the assumption of normality was justified we performed an IRREML (Iterative Reweighted Residual Maximum Likelihood procedure; Engel and Keen 1994) in which the effects were the herd, the selected groups and the situations. The random effects were day and part of the day. When the IRREML results indicated that the assumption of normality was justified, only the ANOVA results were used. The same model was used for testing the data from the AMS. Per experimental situation the average number of visits per cow per day (total, milking, nonmilking and failed milkings) was determined for the entire herd over $7 \mathrm{~d}$ in ES1 and $5 \mathrm{~d}$ in ES2 (due to technical problems) around the observation period. For each individual cow in the Hfreq and Lfreq group the average number of visits (total, milking, nonmilking and failed milkings) was calculated over a total of $7 \mathrm{~d}$ around the observation period (no effect of technical problems).

In testing of the number of visits to the AMS, we used the amount of concentrate ration as a covariate, assuming that this amount could influence these variables. As the concentrate ration per cow was calculated on the basis of milk production, this ration was not used as a covariate in the analysis of milk production.

ANOVA was also used to analyze the number of fetched cows per day. A total of $4 \mathrm{~d}$ per observation week was used.

\section{RESULTS}

\section{Behavioral Pattern in the Barn}

Daily time budget. In the semiforced cow traffic situation the herd ate significantly longer than in the forced cow traffic situation ( $17.4 \%$ vs. $15.1 \% \pm 0.59 \%$ of the day; $P<0.001)$ and stood significantly less in freestalls $(9.0 \%$ vs. $11.8 \% \pm 0.30 \%$ of the day; $P<0.001)$. There was no significant difference between the forced cow traffic situation and the semiforced cow traffic situation in time spent lying $(48.6 \%$ vs. $49.0 \% \pm 0.82 \%$ of the day) or standing on the floor $(25.0 \%$ vs. $24.1 \% \pm$ $0.65 \%$ of the day). 
Table 1. Percentage of time spent on activity and use of the barn by the groups in the two situations.

\begin{tabular}{|c|c|c|c|c|c|c|}
\hline \multirow[b]{2}{*}{$\begin{array}{l}\text { Situation } \\
\text { Number of cows }\end{array}$} & \multicolumn{2}{|c|}{ Lfreq cows } & \multicolumn{2}{|c|}{ Hfreq cows } & \multirow[b]{2}{*}{ s.e.d. ${ }^{1}$} & \multirow[b]{2}{*}{ P-value ${ }^{2}$} \\
\hline & $\begin{array}{l}\mathrm{ES} 1, \\
\text { forced } \\
8\end{array}$ & $\begin{array}{l}\text { ES2, } \\
\text { semiforced } \\
8\end{array}$ & $\begin{array}{l}\text { ES1, } \\
\text { forced } \\
7\end{array}$ & $\begin{array}{l}\text { ES2, } \\
\text { semiforced } \\
7\end{array}$ & & \\
\hline Eating (\%) & 16.7 & 17.0 & 16.6 & 18.7 & 1.50 & NS \\
\hline Standing in freestalls $(\%)$ & $12.9^{\mathrm{a}}$ & $9.7^{\mathrm{b}}$ & $7.4^{\mathrm{c}}$ & $6.3^{\mathrm{c}}$ & 0.85 & $<0.001$ \\
\hline Lying (\%) & 51.8 & 50.0 & 50.0 & 51.4 & 2.45 & NS \\
\hline Standing on floor (\%) & $18.7^{\mathrm{b}}$ & $23.2^{\mathrm{a}}$ & $26.1^{\mathrm{a}}$ & $23.6^{\mathrm{a}}$ & 1.51 & $<0.001$ \\
\hline Feeding area $1(\%)$ & $8.0^{\mathrm{b}}$ & $11.2^{\mathrm{a}}$ & $7.5^{\mathrm{b}}$ & $3.6^{\mathrm{c}}$ & 1.11 & $<0.001$ \\
\hline Feeding area $2(\%)$ & 10.8 & 11.1 & 10.1 & 10.5 & 1.29 & NS \\
\hline Feeding area $3(\%)$ & $5.0^{\mathrm{c}}$ & $5.7^{\mathrm{c}}$ & $10.3^{\mathrm{b}}$ & $17.3^{\mathrm{a}}$ & 1.74 & $<0.001$ \\
\hline Lying area $1(\%)$ & $20.3^{\mathrm{a}}$ & $22.8^{\mathrm{a}}$ & $12.6^{\mathrm{b}}$ & $4.6^{\mathrm{c}}$ & 2.85 & $<0.001$ \\
\hline Lying area $2(\%)$ & $24.3^{\mathrm{a}}$ & $27.5^{\mathrm{a}}$ & $14.7^{\mathrm{b}}$ & $9.5^{\mathrm{b}}$ & 3.11 & $<0.001$ \\
\hline Lying area $3(\%)$ & $24.5^{\mathrm{c}}$ & $13.4^{\mathrm{d}}$ & $36.2^{\mathrm{b}}$ & $48.8^{\mathrm{a}}$ & 3.65 & $<0.001$ \\
\hline Waiting area (\%) & $5.3^{\mathrm{a}, \mathrm{b}}$ & $6.1^{\mathrm{a}, \mathrm{b}}$ & $6.3^{\mathrm{a}}$ & $4.2^{\mathrm{b}}$ & 1.04 & NS \\
\hline $\operatorname{AMS}(\%)$ & $1.8^{\mathrm{a}, \mathrm{b}}$ & $2.3^{\mathrm{a}, \mathrm{b}}$ & $2.4^{\mathrm{a}}$ & $1.6^{\mathrm{b}}$ & 0.36 & NS \\
\hline
\end{tabular}

There were interactions between the Hfreq and Lfreq groups and the experimental situations in the time spent standing in freestalls $(P<0.001)$ and the time spent standing on the floor $(P<0.001$; Table 1$)$.

In ES1 the Hfreq cows stood significantly less in freestalls than the Lfreq cows $(7.4 \%$ versus $12.9 \% ; P<$ 0.05). In the semiforced cow traffic the Lfreq cows stood significantly less in the freestalls than in the forced cow traffic situation $(9.7 \%$ versus $12.9 \% ; P<0.05)$, but this was still more than the Hfreq cows in either situation.

During forced cow traffic the Lfreq cows stood on the floor significantly less than the Hfreq cows (18.7\% versus $26.1 \% ; P<0.05)$. During semiforced cow traffic both groups stood on the floor on average for $23.4 \%$ of the day.

The use of the different areas in the barn. Compared to the forced cow traffic situation, the herd spent significantly more time in feeding area 3 during semiforced cow traffic $(9.9 \%$ versus $6.2 \pm 0.32 \% ; P<0.001)$. Further, in ES2 they were observed significantly less in lying areas 1 (19.8\% versus $21.6 \pm 0.38 \% ; P<0.001$ ) and $2(18.6 \%$ versus $19.7 \pm 0.34 \% ; P<0.01)$ and in the waiting area $(5.8 \%$ versus $6.7 \pm 0.39 \%, P<0.05)$.

There were interactions between the selected groups and the experimental situations (Table 1). The Lfreq cows spent more time close to the AMS in the semiforced situation compared to the forced cow traffic and compared to the Hfreq cows $(P<0.05)$ (Table 1). This Hfreq group spent significantly more time in the end of the barn far from the AMS, compared to the forced cow traffic and the Lfreq cows $(P<0.05)$ (Table 1$)$.

Another difference between the groups was the use of the AMS. During semiforced cow traffic, the Hfreq cows spent significantly less time in the AMS compared to forced cow traffic $(1.6 \%$ versus $2.4 \% ; P<0.05)$. For the Lfreq cows, no significant difference was observed.

\section{Cows' Visits to the AMS}

All visits. The total number of visits did not differ significantly for the herd in the two traffic situations (5.1 in ES1 and $4.8 \pm 0.2$ in ES2; $\mathrm{P}=0.15$ ). For the selected cows we found an interaction between group and situation $(P<0.001$; Table 2$)$. The Hfreq cows visited the AMS significantly less in the semiforced situation (7.4 versus $4.7 ; P<0.05$ ), while the Lfreq cows paid numerically more (4.4 versus 3.5 : NS) visits in the semiforced situation.

Milking visits. For the herd there was no significant difference between ES1 and ES2 in number of AMS visits with milking $(2.8 \pm 0.06$ in both situations; $P=$ $0.64)$. For the selected groups an interaction was found between group and situation $(P<0.001)$. In ES1, the Hfreq cows paid significantly more milking visits than the Lfreq cows (3.1 versus $2.5 ; P<0.05)$. In ES2, the Hfreq cows paid significantly less milking visits than in ES1 (2.9 versus 3.1; $P<0.05$ ), while the Lfreq cows had similar milking visits in each situation.

Nonmilking visits. There tended to be less nonmilking visits to the AMS with the semiforced cow traffic than with the forced cow traffic (1.9 versus $2.2 \pm 0.2 ; P$ $=0.097)$. For the selected cows an interaction between group and situation was found $(P<0.001)$. In ES1 the Hfreq cows paid significantly more nonmilking visits to the AMS than the Lfreq cows (4.2 versus $1.0 ; P<$ 0.05). During semiforced cow traffic the Hfreq cows paid significantly less nonmilking visits (1.8 versus $4.2 ; P$ $<0.05$ ), while the Lfreq cows had numerically more nonmilking visits (1.5 versus 1.0 ; NS). 
Table 2. Mean number of visits to the AMS, milk production and concentrate ration of groups in the two situations.

\begin{tabular}{|c|c|c|c|c|c|c|}
\hline \multirow[b]{2}{*}{$\begin{array}{l}\text { Situation } \\
\text { Number of cows }\end{array}$} & \multicolumn{2}{|c|}{ Lfreq cows } & \multicolumn{2}{|c|}{ Hfreq cows } & \multirow[b]{2}{*}{ s.e.d. ${ }^{1}$} & \multirow[b]{2}{*}{$P$-value ${ }^{2}$} \\
\hline & $\begin{array}{l}\text { ES1, } \\
\text { forced } \\
8\end{array}$ & $\begin{array}{l}\text { ES2, } \\
\text { semiforced } \\
8\end{array}$ & $\begin{array}{l}\mathrm{ES} 1, \\
\text { forced } \\
7\end{array}$ & $\begin{array}{l}\text { ES2, } \\
\text { semiforced } \\
7\end{array}$ & & \\
\hline Mean number of AMS visits/d per cow & $3.5^{\mathrm{b}}$ & $4.4^{\mathrm{b}}$ & $7.4^{\mathrm{a}}$ & $4.7^{\mathrm{b}}$ & 0.78 & $<0.001$ \\
\hline Mean number of milking visits/d per cow & $2.5^{\mathrm{c}}$ & $2.6^{\mathrm{c}}$ & $3.1^{\mathrm{a}}$ & $2.9^{\mathrm{b}}$ & 0.11 & $<0.001$ \\
\hline Mean number of nonmilking visits/d per cow & $1.0^{\mathrm{b}}$ & $1.5^{\mathrm{b}}$ & $4.2^{\mathrm{a}}$ & $1.8^{\mathrm{b}}$ & 0.73 & $<0.001$ \\
\hline Mean number of failed milkings/d per cow & $0.04^{\mathrm{b}}$ & $0.29^{\mathrm{a}}$ & $0.02^{\mathrm{b}}$ & $0.00^{\mathrm{b}}$ & 0.106 & $<0.05$ \\
\hline Mean milk production ( $\mathrm{kg} / \mathrm{d}$ per cow) & 27.2 & 26.6 & 26.6 & 21.3 & 2.93 & NS \\
\hline
\end{tabular}

${ }^{\mathrm{a}, \mathrm{b}, \mathrm{c}}$ Means with different subscripts within a row differ significantly $(P<0.05)$.

${ }^{1}$ s.e.d. is the standard error of differences of means.

${ }^{2} P$-value of the interaction between groups and situations.

Failed milkings. For the herd there were no significant differences found in number of failed attachments between both traffic situations ( 0.10 in ES1 versus 0.15 \pm 0.02 in ES2; $P=0.12$ ). An interaction between group and situation was found for the selected cows $(P<0.05)$. In ES2 the Lfreq cows had more failed attachments than the Hfreq cows $(0.29$ versus $0.00 ; P<0.05)$ and also more failed attachments compared to ES1 (0.29 versus $0.04 ; P<0.05$ ).

Milk yield. The milk production of the herd was significantly lower in the second situation compared to the first ( 25.8 versus $28.0 \pm 0.4 \mathrm{~kg}$ per cow; $P<0.001$ ). For the groups there was no effect of group or situation, the selected cows produced on average $25.5 \mathrm{~kg}$ per day.

Fetching. In ES1 and ES2 on average respectively 2.5 and $5.0 \pm 1.44$ cows of the whole herd $(P=0.134)$ were per day brought to the AMS. Over the $4 \mathrm{~d}$ of analyses in ES1 two Lfreq and no Hfreq cows were fetched, in ES2 three Lfreq cows were fetched and one Hfreq cow. These were five different cows.

\section{DISCUSSION}

\section{The Herd's Response to the Traffic Situations}

The finding that during the semiforced traffic situation (ES2) the cows stood in the freestalls less than in ES1 implies that they were more at ease in ES2, as it has been shown that standing in freestalls for a long time indicates discomfort or discontent (Albright, 1987). However, the cows probably stood in the freestalls less in ES2 because they had free access to part of the feeding area. Evidence to support this is the finding that in ES2 the cows ate significantly longer.

Uetake et al., (1997) found that a waiting area in front of an AMS hampered the cows from synchronizing their feeding and eating as a herd; they also reported that cows milked in an AMS with a waiting area spent less time eating than cows milked in a conventional milking parlor. In our study the free access to the feeding area in ES2 made it easier for cows to eat at the same time as their herd mates. In this situation cows ate significantly longer and also stayed significantly longer in the free feeding area. Our findings are thus in line with the results of Uetake et al., (1997). Winter and Hillerton (1995) also found less synchrony when milking with an AMS, but instead of a decrease in eating time they found that the cows spent less time lying. We did not find any difference in total lying time.

Our finding that in the semiforced traffic situation (ES2) the cows spent more time in the end of the barn furthest away from the AMS can be explained by the feeding area being freely accessible. The cows spent more time there than in the situation with forced traffic (ES1) where this area was not directly accessible from the lying area. The cows also spent more time lying in the lying area far away from the AMS and less time lying in the middle of the barn. The reason could be that they wanted to lie close to the entrance of the feeding area. In ES1 the lying areas in the middle and the front of the barn were actually closest to the entrance of the AMS and therefore close to the feeding area.

The change from ES1 to ES2 resulted in few changes in visits to the AMS. Only the number of nonmilking visits per day per cow tended to decrease. Here also the presence of the freely accessible feeding area could have had an effect. Cows interested in feed could go straight to the feeding area, instead of having to go through the AMS.

The milk production was not corrected for stage of lactation and the decrease in milk production that we found between the experimental situations was probably mainly caused by the course of lactation. The cows in our experiment were on average $109 \mathrm{~d}$ in lactation. After about $90 \mathrm{~d}$ of lactation the rate of decline in milk yield is normally 1.5 to $2.0 \%$ per week (Webster, 1993). 
The Response of the Selected Groups to the Traffic Situations

The interactions between group and experimental situation we found when we compared the Hfreq group with the Lfreq group suggest that the groups reacted differently to the two situations. The daily time budgets of the groups were more similar in the semiforced traffic situation (ES2) than in the forced cow traffic situation (ES1). The Hfreq cows stood less and the Lfreq cows stood more, with the result that both groups stood on the floor for $23 \%$ of the day. The Hfreq cows paid significantly fewer visits to the AMS and thus spent less time walking to the waiting area and standing in the waiting area and in the AMS. The time saved was counted as standing on the floor.

Though the Lfreq cows visited the AMS more, the Hfreq cows still had significantly more milking visits. This seems to be caused by the number of failed milkings. In the semiforced traffic situation, the Lfreq cows had significantly more failed milkings than the Hfreq cows and it thus reduced the number of milking visits the Lfreq cows could have under the same visiting frequency.

The Lfreq cows stood less in freestalls than Hfreq cows, which indicates that they "liked" the second situation better than the first, but they still stood more in the freestalls than the Hfreq cows did.

In the semiforced traffic the Hfreq cows spent more time in the end of the barn, as did most of the herd, whereas the Lfreq cows spent more time in the middle and the front of the barn. Maybe the Lfreq cows were trying to avoid the crowd of the herd and, in particular, the Hfreq cows. This might be related to the dominance of the animals in the herd (Beilharz and Zeeb 1982). If the Lfreq cows were subordinate they would have had no chance of appropriating one of the limited number of freestalls in the back of the barn (a limited resource; Barroso et al., 2000).

\section{Number of Visits in the Observation Weeks}

The selected cows were retained in their groups throughout the experiment, even when they did not meet the selection criterion in the observation week. Ultimately there was only one cow (Hfreq group) that did not change her visiting patterns in ES1 and ES2.

In the observation weeks in ES1 and ES2 there were other cows that were not selected but did meet the selection criterion. Some of these cows had been added to the herd after the selection week or after the first observation week. All these cows were very frequent visitors and most of them had just calved (less than 30 $\mathrm{d}$ previously). Maybe these cows visited the AMS often because they were trying to develop a visiting pattern (if cows can visit the feeding area freely, they tend to feed seven to ten times a day: Pirkelmann, 1992); after a while they would have visited the AMS less, because it took so much time to go through the AMS.

\section{The Individual Cows}

There were some differences between individual cows in the two selected groups. These were not only in the way they used the barn and in their daily time budget, but also in the way they responded to the change of traffic situation. Some cows did not respond to the change, whereas others completely changed their activity and use of the barn. So although there were group effects after the change of situation, the individual cows within the groups did not respond in the same way.

\section{General Comments}

The freely available feeding area was rather small (18 feeding places). We chose that size of feeding area because we wanted to be sure that the cows would visit the AMS often enough. A larger freely accessible feeding area would have given more cows an opportunity to eat there at the same time and fewer cows would have visited the AMS often enough. It is possible that the dominance hierarchy in the herd prevented the less dominant cows from going to the freely accessible feeding area at will, especially around the time the forage was provided. If dominance were influential, this would mean that low-ranking cows would have had more opportunities to visit the AMS and eat forage in feeding areas one and two in ES2 because the high-ranking cows would have gone to the freely accessible feeding area.

After ES2 the barn layout was changed back to ES1, we were unable to have an observation period after that change. Although it is recognized that contemporary comparisons with a switchback of treatments are desirable, the availability of only one robotic milker prevented such a comparison. However, we believe that the observed change in use of the barn and activity of the cows was mainly caused by the change in cow traffic situation rather than by change over time.

\section{CONCLUSIONS}

We conclude that the layout with semiforced traffic is superior in two aspects. The finding that in this layout the cows spent more time at the feeding gate and less time standing in freestalls indicates that this layout is better suited to cow behavior than the layout with the forced cow traffic. Furthermore, the fact that there was a tendency to a decrease in nonmilking visits and no 
change in the number of milking visits indicates that this layout better exploits the AMS' capacity.

In the situation with semiforced cow traffic the visits to the AMS were more equally divided among the cows than in the forced cow traffic situation. As a result fewer cows visited the AMS very frequently or very infrequently.

When milking with an automatic milking system the cow traffic should be organized as optimally as possible for the cow and for the capacity of the AMS. The results of this study comparing forced cow traffic with semiforced cow traffic plus a freely available feeding area indicate that some direct access to forage is better for the cows and for the AMS capacity. This knowledge can be used when installing an AMS.

\section{ACKNOWLEDGMENTS}

The authors would like to thank Derk-Jan Haverkamp, Joan van Eijk, Ronald Bakker and Jarno Jansen for their help with the observations. Further we would like to thank J.V. van den Berg for his help with the statistics and P.H. Hogewerf for the drawing of the barn layout. The staff of "De Ossekampen" experimental farm is thanked for assistance. The authors' editor was Joy Burrough.

\section{REFERENCES}

Albright, J. L. 1987. Dairy animal welfare: current and needed research. J. Dairy Sci. 70:2711-2731.

Barroso, F. G., C. L. Alados, J. Boza. 2000. Social hierarchy in the domestic goat: effect on food habits and production. Appl. Anim. Behav. Sci. 69:35-53.

Beilharz, R. G., and K. Zeeb. 1982. Social dominance in dairy cattle. Appl. Anim. Ethol. 8:79-97.

Engel, B., and A. Keen. 1994. A simple approach for the analysis of generalized linear mixed models. Statistica Neerlandica 48:1-22.

GenStat 5 committee 1999. GenStat 5 Release 4.1. 4th ed. Lawes agricultural Trust IACR- Rothamsted, England.
Harms, J., G. Wendl, and H. Schön. 2001. Untersuchungen zum Einfluss verschiedener Umtriebsformen auf das Tier- und Melkverhalten beim automatischen Melken [Influence of different forms of cow traffic on the animal and milking behavior in automatic milking systems]. Pages 236-241 in Tagung: Bau, Technik und Umwelt 2001. Institut für Agrartechnik der Universität Hohenheim, ed. [Conference: Construction, Engineering and Environment in Livestock Farming, in German with English summary], Hohenheim, Germany.

Hurnik, J. F. 1992. Ethology and technology: the role of ethology in automation of animal production processes. Pages 401-408 in Prospects for automatic milking. A. H. Ipema, A. C. Lippus, J. H. M. Metz, and W. Rossing eds. Proc. Int. Symp., Pudoc Scientific Publishers, Wageningen.

Ipema, A. H. 1997. Integration of robotic milking in dairy housing systems; Review of cow traffic and milking capacity aspects. Computers and Electronics in Agriculture 17:79-94.

Ketelaar-de Lauwere, C. C. 1992. The use of a selection unit for automatic milking: consequences for cow behavior and welfare. Pages 270-277 in Prospects for automatic milking. A. H. Ipema, A. C. Lippus, J. H. M. Metz, and W. Rossing, eds. Proc. Int. Symp., Pudoc Scientific Publishers, Wageningen.

Ketelaar-de Lauwere, C. C., M. M. W. B. Hendriks, J. H. M. Metz, and W. G. P. Schouten. 1998. Behavior of dairy cows under free or forced cow traffic in a simulated automatic milking system environment. Appl. Anim. Behav. Sci. 56:13-28.

Ketelaar-de Lauwere, C. C., M. M. W. B. Hendriks, J. Zondag, A. H. Ipema, J. H. M. Metz, and J. P. T. M. Noordhuizen. 2000. The influence of routing treatments on cows' visits to an automatic milking system, their time budget and other behavior. Acta Agric. Scand. Section A, Animal science 50(3):174-183.

Metz-Stefanowska, J., C. C. Ketelaar-de Lauwere, A. H. Ipema, and P. J. M. Huijsmans. 1992. Mogelijkheden om het koeverkeer te beïnvloeden ten behoeve van het automatisch melken [Influencing cow traffic for the purpose of automatic milking]. IMAG-DLO report $92-13$, Wageningen, the Netherlands.

Pirkelmann, H. 1992. Feeding strategies and automatic milking. Pages 289-295 in Prospects for automatic milking. A. H. Ipema, A. C. Lippus, J. H. M. Metz, and W. Rossing, eds. Proc. Int. Symp. Pudoc Scientific Publishers, Wageningen.

Prescott, N. B., T. T. Mottram, and A. J. F. Webster. 1998. Relative motivations of dairy cows to be milked or fed in a Y-maze and an automatic milking system. Appl. Anim. Behav. Sci. 57:23-33.

Uetake, K., J. F. Hurnik, and L. Johnson. 1997. Behavioral pattern of dairy cows milked in a two-stall automatic milking system with a holding area. J. Anim. Sci. 75:954-958.

Webster, J. 1993. Understanding the dairy cow. 2nd Edition, Blackwell Science, Oxford.

Winter, A., and J. E. Hillerton. 1995. Behavior associated with feeding and milking of early lactation cows housed in an experimental automatic milking system. Appl. Anim. Behav. Sci. 46:1-15. 